\title{
Cost-effectiveness of fibronectin testing in a triage in women with threatened preterm labor: alleviation of pregnancy outcome by suspending tocolysis in early labor (APOSTEL-I trial)
} Jolande Y Vis*1, Femke F Wilms ${ }^{2}$, Martijn A Oudijk ${ }^{1}$, Martina M Porath ${ }^{2}$, Hubertina CJ Scheepers ${ }^{3}$, Kitty WM Bloemenkamp ${ }^{4}$, Annemiek C Bolte ${ }^{5}$, Jérôme Cornette ${ }^{6}$, Jan B Derks ${ }^{7}$, Johannes J Duvekot ${ }^{6}$, Jim van Eyck ${ }^{8}$, Anneke Kwee ${ }^{7}$, Brent C Opmeer ${ }^{9}$, Maria G van Pampus ${ }^{10}$, Fred K Lotgering ${ }^{11}$, Sicco A Scherjon ${ }^{4}$, Krystyna M Sollie ${ }^{10}$, Marc EA Spaanderman ${ }^{11}$, Christine Willekes ${ }^{3}$, Joris AM van der Post ${ }^{1}$ and Ben Willem J Mol${ }^{1}$

Address: ${ }^{1}$ Department of Obstetrics and Gynaecology, Academic Medical Centre, Amsterdam, The Netherlands, ${ }^{2}$ Department of Obstetrics and Gynaecology, Máxima Medical Centre, Veldhoven, The Netherlands, ${ }^{3}$ Department of Obstetrics and Gynaecology, Maastricht University Medical Centre, Maastricht, The Netherlands, ${ }^{4}$ Department of Obstetrics and Gynaecology, Leiden University Medical Centre, Leiden, The Netherlands, ${ }^{5}$ Department of Obstetrics and Gynaecology, VU Medical Centre, Amsterdam, The Netherlands, ${ }^{6}$ Department of Obstetrics and Gynaecology, Erasmus Medical Centre, Rotterdam, The Netherlands, ${ }^{7}$ Department of Obstetrics and Gynaecology, University Medical Centre, Utrecht, The Netherlands, ${ }^{8}$ Department of Obstetrics and Gynaecology, Isala Clinics, Zwolle, The Netherlands, ${ }^{9}$ Department of Clinical Epidemiology, Biostatistics and Bioinformatics, Academic Medical Centre, Amsterdam, The Netherlands, ${ }^{10}$ Department of Obstetrics and Gynaecology, University Medical Centre, Groningen, The Netherlands and ${ }^{11}$ Department of Obstetrics and Gynaecology, Radboud University Nijmegen Medical Centre, Nijmegen, The Netherlands

Email: Jolande Y Vis* - j.y.vis@amc.nl; Femke F Wilms - femke_wilms@hotmail.com; Martijn A Oudijk - m.a.oudijk@amc.uva.nl; Martina M Porath - m.porath@mmc.nl; Hubertina CJ Scheepers - hcj.scheepers@mumc.nl;

Kitty WM Bloemenkamp - k.w.m.bloemenkamp@lumc.nl; Annemiek C Bolte - ac.bolte@vumc.nl; Jérôme Cornette - j.cornette@erasmusmc.nl; Jan B Derks - j.b.derks@umcutrecht.nl; Johannes J Duvekot - j.j.duvekot@erasmusmc.nl; Jim van Eyck - jvaneyck@wxs.nl;

Anneke Kwee - a.kwee@umcutrecht.nl; Brent C Opmeer - b.c.opmeer@amc.uva.nl; Maria G van Pampus - m.van.pampus@og.umcg.nl;

Fred K Lotgering - f.lotgering@obgyn.umcn.nl; Sicco A Scherjon - s.scherjon@lumc.nl; Krystyna M Sollie - k.m.sollie@og.umcg.nl;

Marc EA Spaanderman - m.spaanderman@obgyn.umcn.nl; Christine Willekes - c.willekes@mumc.nl; Joris AM van der

Post - j.a.vanderpost@amc.uva.nl; Ben Willem J Mol - b.w.mol@amc.uva.nl

* Corresponding author

Published: I September 2009

BMC Pregnancy and Childbirth 2009, 9:38 doi:10.1 186/147/-2393-9-38

This article is available from: http://www.biomedcentral.com/I47/-2393/9/38

(C) 2009 Vis et al; licensee BioMed Central Ltd.

This is an Open Access article distributed under the terms of the Creative Commons Attribution License (http://creativecommons.org/licenses/by/2.0), which permits unrestricted use, distribution, and reproduction in any medium, provided the original work is properly cited.

\begin{abstract}
Background: At present, women with threatened preterm labor before 32 weeks of gestation are, after transfer to a perinatal center, treated with tocolytics and corticosteroids. Many of these women are treated unnecessarily. Fibronectin is an accurate predictor for the occurrence of preterm birth among women with threatened preterm labor. We will assess whether triage of these women with fibronectin testing, cervical length or their combination is cost-effective.

Methods/Design: We will investigate a prospective cohort of women referred to a perinatal centre for spontaneous threatened preterm labor between 24 and 34 weeks with intact membranes. All women will be tested for fibronectin and cervical length. Women with a cervical length $<10 \mathrm{~mm}$ and women with a cervical length between $10-30 \mathrm{~mm}$ in combination with a positive fibronectin test will be treated with tocolytics according to local protocol. Women with a cervical
\end{abstract}


length between 10-30 $\mathrm{mm}$ in combination with a negative fibronectin test will be randomised between treatment with nifedipine (intervention) and placebo (control) for 48 hours. Women with a cervical length $>30 \mathrm{~mm}$ will be managed according to local protocol. Corticosteroids may be given to all women at the discretion of the attending physician. Primary outcome measure will be delivery within 7 days. Secondary outcome measures will be neonatal morbidity and mortality, complications of tocolytics, costs and health related quality of life. The analysis will be according to the intention to treat principle. We anticipate the probability on preterm birth within 7 days in the group of women with a negative fibronectine test to be $5 \%$. Two groups of 110 women will be needed to assure that in case of non-inferiority the difference in the proportion of preterm deliveries $<7$ days will be within a prespecified boundary of $7.5 \%$ (one sided test, $\beta 0.2, \alpha 0.05$ ). Data obtained from women with a positive and negative fibronectin tests in both the cohort study and the trial will be integrated in a cost-effectiveness analysis that will assess economic consequences of the use of fibronectin.

Discussion: This study will provide evidence for the use of fibronectin testing as safe and costeffective method in a triage for threatened preterm labor.

Trial registration: Nederlands Trial Register (NTR) number 1857, http://www.trialregister.nl.

\section{Background}

Preterm birth is the most frequent cause of perinatal mortality and severe perinatal morbidity in the Western world [1]. Preterm birth can be preceded by rupture of the membranes and/or by uterine contractions leading to cervical effacement and dilation. Current treatment of women with threatened preterm labor is tocolysis to diminish contractions and the administration of corticosteroids to enhance fetal lung development [2]. In the Netherlands, $7.9 \%$ of all deliveries are preterm, and $1.6 \%$ of all neonates are born before 32 weeks of gestation [3]. Women at risk for preterm birth prior to 32 weeks are transferred to a perinatal centre [4].

Discriminating those women who will deliver preterm is difficult: about half of the women treated with tocolytics and/or corticosteroids do not deliver within a short time after the occurrence of symptoms. As tocolytics and corticosteroids can cause severe side-effects in both mother and child [5-8], concerns have been expressed about overtreatment. If we are able to identify women that eventually do not deliver preterm and thus do not benefit from referral and treatment, we could prevent them from being exposed to the potential side effects of tocolytics and corticosteroids. In addition, management costs could be reduced by preventing unnecessary transport of pregnant women to perinatal centers and the associated higher treatment costs.

Fetal fibronectin is an internationally accepted predictor of preterm birth [9]. Fetal fibronectin is a glycoprotein found in amniotic fluid, placental tissue, and the extracellular substance of the decidua next to the placental intervillous space. It is thought to be released through mechanical or inflammatory mediated damage to the membranes or placenta before birth [10]. Swabs can be taken from the ectocervix or posterior vaginal fornix, and an enzyme linked immunosorbent assay (ELISA) containing FDC6 monoclonal antibody can be used to detect fetal fibronectin [11]. The results may indicate the likelihood of spontaneous preterm birth [12]. In clinical use, however, factors such as contamination of the sample with maternal blood, sampling within 24 hours after intercourse, and preeclampsia may reduce the accuracy of the test and give false positive results [13-15].

The predictive capacity of fibronectin has been the topic of previous studies. Honest and co-workers published in 2002 a systematic review on the predictive capacity of fibronectin for preterm delivery [16]. They identified 40 studies reporting on symptomatic women. The summary likelihood ratio for a positive result was 5.4 (95\% CI 4.4 to 6.7 ) for predicting birth within 7 to 10 days of testing, with a corresponding likelihood ratio for a negative result of 0.25 (95\% CI 0.20 to 0.31 ). Therefore fibronectin testing might be able to reduce unnecessary treatment and subsequent costs. On the other hand, introducing fibronectin tests has not yet proven to reduce health care costs if the subsequent management is subject to physicians preferences [17-21]. In addition, high false positive rates may increase health care costs in the management of low risk women.

For cervical length measurement, the situation is different. This test is shown to predict preterm delivery in asymptomatic women at 20 weeks [22]. However, the accuracy of the test is only marginally evaluated in women with symptoms of preterm labor at a later gestational age [23]. Gomez et al. evaluated the predictive accuracy of a combination of fetal fibronectin measurement and cervical 
length measurement [24]. In their study, $15 \%$ of the women had cervical lengths below $15 \mathrm{~mm}$, and one third of these women delivered within 48 hours. Among those with a cervical length between $15 \mathrm{~mm}$ and $30 \mathrm{~mm}$ (36\% of the population), $25 \%$ had a positive fibronectin test, and $15 \%$ of this group delivered within 48 hours. Of the remaining $75 \%$ of the women, less than $5 \%$ delivered within 7 days. These results are comparable with our pilot study of Wilms et al. Amongst 19 women with a cervical length between $10-30 \mathrm{~mm}$ and a negative fibronectin test, only 1 woman delivered within 7 days[25].

At present, fibronectin testing is not routinely used in The Netherlands. To assess the risk for threatened preterm labor, only cervical length is routinely measured[2]. This measurement is frequently used as an argument to transfer and treat women for threatened preterm labor, even if clinical symptoms are mild. Identifying women that are at high risk for preterm delivery could benefit from adding fibronectin testing. Therefore we will evaluate if adding fibronectin testing to cervical length measurement is a safe and cost-effective strategy as a triage for women with threatened preterm labor.

\section{Methods/Design}

\section{Aims}

We will evaluate a risk assessment with fibronectin testing for women with clinical signs of threatened preterm labor. We will assess whether triage of these women with fibronectin testing, cervical length measurements or a combination is cost-effective. The results of this study can be used to support a policy of expectant management without immediate referral to a neonatal centre and without tocolysis in women with a low risk for preterm birth.

\section{Participants/eligibility criteria}

All women between 24 and 34 weeks of gestational age with primary complaints associated with preterm labor and intact membranes will be eligible for inclusion in the study. Women with vaginal bleeding, a cerclage, cervical dilatation of more than $3 \mathrm{~cm}$ or previous treatment for threatened preterm labor in the current pregnancy are excluded. Other exclusion criteria are hypertension, contra indications for nifedipine and fetal distress or maternal conditions that may lead to pregnancy termination within 7 days. The study will be limited to women admitted to a perinatal centre with neonatal intensive care facilities.

\section{Procedures, recruitment, randomisation and collection of baseline data}

Women meeting the eligibility criteria will be informed and invited to participate in the study and asked for written informed consent. At study entry baseline demographics, obstetric and medical history will be recorded. Before cervical length measurement, women will be tested for fibronectin. Therefore a sample of cervicovaginal secretion will be taken by rotating a swab in the posterior vaginal fornix for 10 seconds. Analysis will be performed using the FullTerm $\mathrm{TLi}_{\mathrm{IQ}}$ system of Hologic [26].

Women with a cervical length below $10 \mathrm{~mm}$ and women with a cervical length between $10-30 \mathrm{~mm}$ in combination with a positive fibronectin test will be treated with tocolysis. These women are considered to be at high risk for preterm delivery. Women with a cervical length above $30 \mathrm{~mm}$ will be treated according to the discretion of the physician. Women with a cervical length between $10-30 \mathrm{~mm}$ and a negative fibronectin test are considered to be at low risk, they will enter a double blind trial in which they will be randomised by a central web-based system between tocolytics or placebo (1:1). Details of delivery and maternal assessments during pregnancy of all women are recorded in case record forms (CRF) that are accessible through a closed part of a central website. All data will be collected, coded and processed with adequate precautions to ensure patient confidentiality.

\section{Interventions}

All high risk women will receive tocolytics according to local protocol. Fibronectin negative women with a cervical length between $10-30 \mathrm{~mm}$ will be randomly allocated to tocolytics or placebo (figure 1). Active treatment will be performed with the calcium channel blocking agent nifedipine with a total daily dose between 80 and 120 milligrams for 48 hours. Active drug and placebo will be administered orally at the same volume and rate. Corticosteroids will be administered at the discretion of the attending physician.

Progression of labor will be monitored every 12 hours by means of clinical observation and/or vaginal examinations for 48 hours. If labor seems inevitable in that period, study medication can be stopped and another tocolytic (excluding nifedipine) may be administered.

\section{Follow up of women and infants}

Details of admission of newborns to the neonatal intensive care unit and neonatal complications will be recorded. Long term follow up is not part of this study.

\section{Outcome measures}

The primary outcome measure is number of days to delivery truncated at 7 days after study entry. Secondary endpoints are neonatal mortality, neonatal morbidity, maternal morbidity (side effects of nifedipine), costs and health related quality of life. 


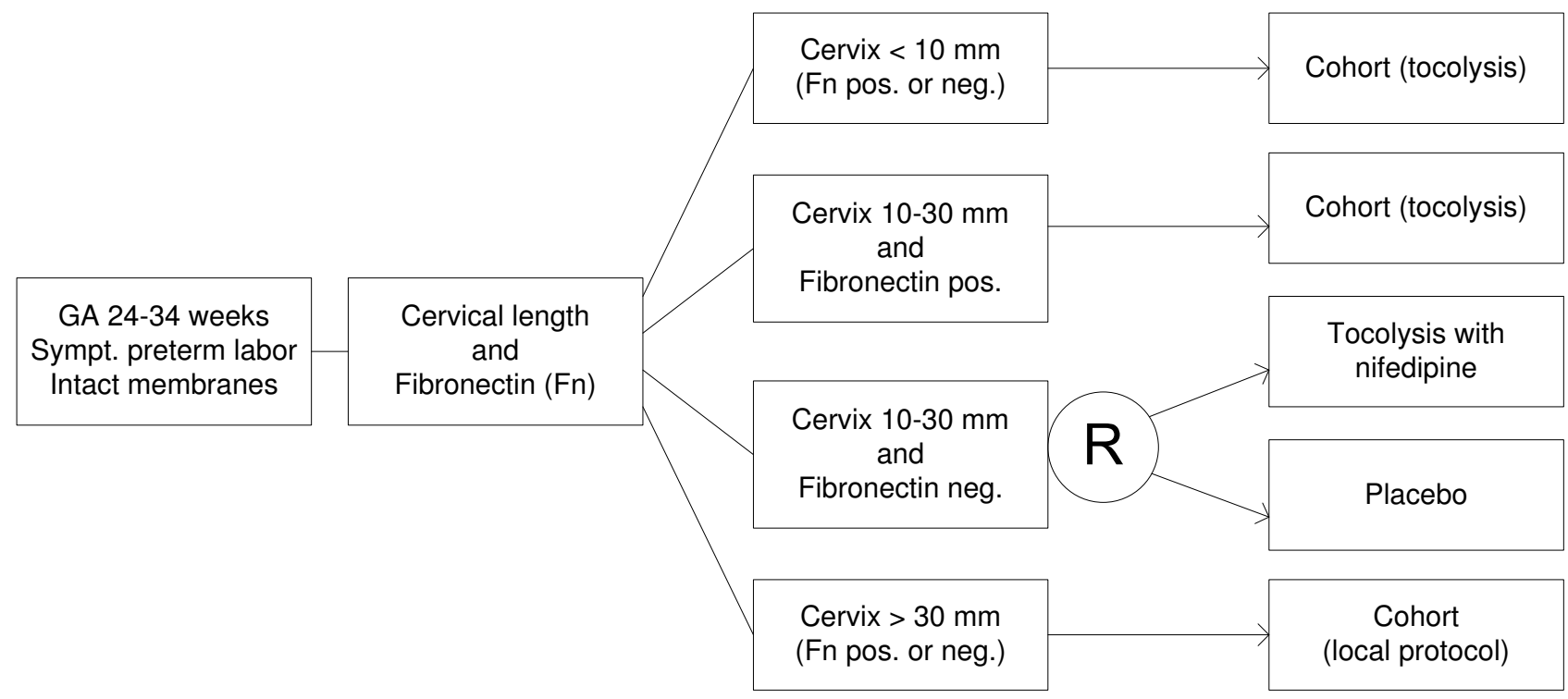

\section{Figure I}

Flow chart APOSTEL-I study, an overview of which patients in the APOSTEL-I cohort will be randomized based on their cervical length and fibronectin status.

\section{Statistical issues}

\section{Sample size}

The randomised trial in our study will be a non-inferiority effectiveness trial. Based on our pilot study [25], we anticipate the probability on preterm birth within 7 days in the group of women with a negative fibronectine test and a cervical length $10-30 \mathrm{~mm}$ to be $5 \%$. We need 220 fibronectin negative women in the cohort (110 per arm) to assure with $80 \%$ power that in case of non-inferiority the upper limit of the $95 \%$ one-sided CI for the difference in the proportion of preterm deliveries $<7$ days will be within a prespecified boundary of $7.5 \%$. According to our pilot we will need a cohort of approximately 660 women [25].

\section{Data analysis}

The results of the randomised trial will be analyzed according to the intention to treat principle. We will analyze costs and effects of a strategy based on fibronectin measurement and cervical length, in which only fibronectin positive women will be transferred to a perinatal center and/or and treated. Costs and effects of this strategy will be compared to a strategy in which these women will be transferred and treated merely based on a clinical diagnosis by e.g. vaginal examination and/or cervical length measurement.

\section{Interim analysis}

After 100 fibronectin negative, low risk women have entered the randomised trial, an interim analysis will be performed by an external independent safety committee. Interim analysis will be performed on the primary outcome only, e.g. percentage of preterm deliveries within 7 days after fibronectin testing. If there is a significant difference between the groups treated with tocolytics and placebo, the independent safety committee will decide about further unblinding of the interim results and (dis)continuation of the trial.

\section{Economic evaluation}

The aim of the economic evaluation is to assess whether fibronectin testing as a triage for women with threatened preterm labor is cost-effective. For the cost analysis we distinguish cost within the antenatal period, during delivery and childbirth and within the postnatal period. As the study will be performed from a societal perspective, three cost categories will be included: direct medical costs, direct non-medical costs and indirect costs. Volumes of health care resource use during the index admission are measured prospectively alongside the clinical study in all participating centers as part of the CRF. Questionnaires addressing health related quality of life will be administered in a random subsample.

If the randomised trial indicates that a particular subgroup of women does not benefit from treatment with tocolytics, the economic analysis will be a cost-minimization analysis. If tocolysis and transferring low risk women would not be necessary, the costs of risk assessment (int.al. fibronectin testing) of the whole cohort of women 
will be compared to the potential cost saving. Furthermore, scenario analyses for relevant subgroups will be performed. Before analyzing the data from the study, a detailed cost analysis model will be developed.

The trial results will be incorporated in a diagnostic model to compare a risk assessment strategy for women with threatening preterm labor within current practice, which does not include additional risk assessment with fibronectin.

The study design will enable us to compare the costs and effects of the following strategies:

I. transfer and treat all women with threatening preterm labor

II. transfer and treat women based on the results of fibronectin measurement. As we also measure cervical length, we can also evaluate the following strategies:

III. transfer and treat women based on the results of cervical length measurement

IV. transfer and treat women based on a combination of cervical length measurement and fibronectin measurement

V. sequential combinations, for example first cervical length measurement, and fibronectin measurement in a part of that women, or vice versa.

In our cohort, we will obtain data on the moment of delivery in women treated with tocolytics and not treated with tocolytics. In addition to our cohort data, we will obtain data from medical literature on the occurrence of neonatal mortality and morbidity in relation to duration of pregnancy, both with and without treatment of corticosteroids. We will use this to calculate the expected neonatal mortality and morbidity for each of the five strategies mentioned above.

\section{Ethical consideration}

This study has been approved by the ethics committee of the Academic Medical Centre Amsterdam (ref.no MEC 08/363).

\section{Discussion}

In women with clinical signs of threatened preterm labor, fibronectin can discriminate between those at low risk and high risk for immediate preterm delivery. Since treatment of low risk women might be unnecessary, testing for fibronectin is thought to be a cost effective strategy. It may protect mother and fetus from possible side effects of tocolytics and corticosteroids, lessen burden of perinatal centers and decrease stress and anxiety for the families. So far, no randomised trial has shown beneficial effects of fibronectin testing for women presenting with threatened preterm labor, despite its high negative predictive value. Although the use of fibronectin tests for these women is already implemented in some clinics and even incorporated into guidelines [27], neither its safety as a triage instrument, nor its cost effectiveness has been established.

We decided to use a fixed protocol to translate the test results into a management strategy with nifedipine, to out rule the influence of individual physicians. Nifedipine has not yet been tested against placebo as a tocolytic drug, though both the Cochrane Collaboration [28] and the Dutch Society of Obstetrics and Gynaecology [2] recommend calcium antagonists as first choice. It is unlikely that using another tocolytic drug would lead to different outcomes of this trial, since fibronectin negative women have a low a priori probability of delivering within 7 days after the test. So even though we randomize on therapy level, this trial will evaluate fibronectin testing and cervical length measurement for women with threatened preterm labor.

\section{Competing interests}

The authors declare that they have no competing interests.

\section{Authors' contributions}

BWJM, JAMvdP, MAO, BO and JYV were involved in conception and design of the study. JYV, MAO and BWJM drafted the first manuscript. All authors mentioned in the manuscript are members of the APOSTEL I study group. They participated in the design of the study during several meetings and are local investigators in the participating centers. All authors edited the manuscript and read and approved the final draft.

\section{Acknowledgements}

This study is funded by ZonMW grant 80-82310-98-09056.

\section{References}

I. Slattery MM, Morrison J]: Preterm delivery. Lancet 2002, 360: 1489-1497.

2. Dutch Society for Obstetrics and Gynaecology (NVOG): Threatened Preterm Labour. Guideline version 2.0 Utrecht, The Netherlands: NVOG; 2004

3. Stichting Perinatale Registratie Nederland: Perinatal Care in the Netherlands 2006 Utrecht: Stichting Perinatale Registratie Nederland; 2008.

4. Dutch Society for Obstetrics and Gynaecology (NVOG): Referral to perinatal centres, collaboration secondary and tertiary hospitals. Policy Document (I.0) Utrecht, The Netherlands: NVOG; 2007.

5. French NP, Hagan R, Evans SF, Mullan A, Newnham JP: Repeated antenatal corticosteroids: effects on cerebral palsy and childhood behavior. Am J Obstet Gynecol 2004, 190:588-595.

6. Oei SG: Calcium channel blockers for tocolysis: a review of their role and safety following reports of serious adverse events. Eur J Obstet Gynecol Reprod Biol 2006, I 26: I37-I 45.

7. van Veen AJ, Pelinck MJ, van Pampus MG, Erwich JJ: Severe hypotension and fetal death due to tocolysis with nifedipine. $B J O G$ 2005, II 2:509-510. 
8. de Heus R, Mol BW, Erwich J], van Geijn HP, Gyselaers WJ, Hanssens $M$, et al: Adverse drug reactions to tocolytic treatment for preterm labour: prospective cohort study. BMJ 2009, 338:b744.

9. American College of Obstetricians and Gynecologists (ACOG): Management of preterm labor Washington (DC): American College of Obstetricians and Gynecologists (ACOG); 2003.

10. Sibille Y, Lwebuga-Mukasa JS, Polomski L, Merrill WW, Ingbar DH, Gee JB: An in vitro model for polymorphonuclear-leukocyteinduced injury to an extracellular matrix. Relative contribution of oxidants and elastase to fibronectin release from amnionic membranes. Am Rev Respir Dis 1986, 134: I34-140.

II. Matsuura H, Takio K, Titani K, Greene T, Levery SB, Salyan ME, et al.: The oncofetal structure of human fibronectin defined by monoclonal antibody FDC-6. Unique structural requirement for the antigenic specificity provided by a glycosylhexapeptide. J Biol Chem 1988, 263:33 I4-3322.

12. Lockwood CJ, Senyei AE, Dische MR, Casal D, Shah KD, Thung SN Jones L, Deligdisch L, Garite TJ: Fetal fibronectin in cervical and vaginal secretions as a predictor of preterm delivery. $N$ Engl J Med 1991, 325:669-674.

13. Shimoya K, Hashimoto K, Shimizu T, Saji F, Murata Y: Effect of sexual intercourse on fetal fibronectin concentration in cervicovaginal secretions. Am J Obstet Gynecol 1998, 179:255-256.

14. Sadovsky $Y$, Friedman SA: Fetal fibronectin and preterm labor. $N$ Engl J Med 1992, 326:709.

15. Brubaker DB, Ross MG, Marinoff D: The function of elevated plasma fibronectin in preeclampsia. Am J Obstet Gynecol 1992, 166:526-531.

16. Honest H, Bachmann LM, Gupta JK, Kleijnen J, Khan KS: Accuracy of cervicovaginal fetal fibronectin test in predicting risk of spontaneous preterm birth: systematic review. BMJ 2002, 325:301.

17. Grobman WA, Welshman EE, Calhoun EA: Does fetal fibronectin use in the diagnosis of preterm labor affect physician behavior and health care costs? A randomized trial. Am J Obstet Gynecol 2004, 191:235-240.

18. Lowe MP, Zimmerman B, Hansen W: Prospective randomized controlled trial of fetal fibronectin on preterm labor management in a tertiary care center. Am J Obstet Gynecol 2004, 190:358-362.

19. Ness A, Visintine J, Ricci E, Berghella V: Does knowledge of cervical length and fetal fibronectin affect management of women with threatened preterm labor? A randomized trial. Am J Obstet Gynecol 2007, I 97:426-427.

20. Plaut MM, Smith W, Kennedy K: Fetal fibronectin: the impact of a rapid test on the treatment of women with preterm labor symptoms. Am J Obstet Gynecol 2003, I 88: I588-1593.

21. Berghella V, Hayes E, Visintine J, Baxter JK: Fetal fibronectin testing for reducing the risk of preterm birth. Cochrane Database Syst Rev 2008:CD006843.

22. Crane JM, Hutchens $D$ : Transvaginal sonographic measurement of cervical length to predict preterm birth in asymptomatic women at increased risk: a systematic review. Ultrasound Obstet Gynecol 2008, 31:579-587.

23. Honest H, Bachmann LM, Coomarasamy A, Gupta JK, Kleijnen J, Khan $\mathrm{KS}$ : Accuracy of cervical transvaginal sonography in predicting preterm birth: a systematic review. Ultrasound Obstet Gynecol 2003, 22:305-322.

24. Gomez R, Romero R, Medina L, Nien JK, Chaiworapongsa T, Carstens $M$, et al.: Cervicovaginal fibronectin improves the prediction of preterm delivery based on sonographic cervical length in patients with preterm uterine contractions and intact membranes. Am / Obstet Gynecol 2005, 192:350-359.

25. Wilms FF, Stralen G, Porath MM, Papatsonis DMN, Oei SG, Mol BW], et al:: Voorspellen van dreigende vroeggeboorte door midde van bepaling van foetaal fibronectine in vaginaal vocht. Nederlands Tijdschrift voor Geneeskunde (Dutch Journal of Medicine) 2009, 153:B398.

26. Fullterm, The fetal fibronectin test. Hologic, Inc. 2-7-2009. Ref Type: Internet Communication

27. American College of Obstetricians and Gynecologists (ACOG): Management of preterm labor Washington (DC): American College of Obstetricians and Gynecologists (ACOG); 2003.
28. King JF, Flenady VJ, Papatsonis DN, Dekker GA, Carbonne B: Calcium channel blockers for inhibiting preterm labour. Cochrane Database Syst Rev 2003:CD002255.

\section{Pre-publication history}

The pre-publication history for this paper can be accessed here:

http://www.biomedcentral.com/1471-2393/9/38/prepub
Publish with Biomed Central and every scientist can read your work free of charge

"BioMed Central will be the most significant development for disseminating the results of biomedical research in our lifetime. "

Sir Paul Nurse, Cancer Research UK

Your research papers will be:

- available free of charge to the entire biomedical community

- peer reviewed and published immediately upon acceptance

- cited in PubMed and archived on PubMed Central

- yours - you keep the copyright
BioMedcentral 